\title{
Design of Microstrip Patch Antenna for Ku-Band Satellite Communication Applications
}

\author{
Settapong Malisuwan, Jesada Sivaraks, Navneet Madan, and Nattakit Suriyakrai
}

\begin{abstract}
A rectangular microstrip patch antenna is presented in this paper for Ku-band satellite communication applications. The proposed E-shaped patch antenna is designed to cover various applications such as broadcasting, remote sensing and space communication. To include the effect of high frequency in the procedure, the concept of microstrip-based Cole-Cole diagram is adopted to create a frequency-dependent (lossy) characteristic impedance. The simple method proposed in this research is compatible with Computer Aided Design (CAD) and hence, design of microstrip antenna for Ku Band satellite from this research will be fast and easy to implement.
\end{abstract}

Index Terms-Microstrip antenna, ku-band, e-shaped, frequency-dependent, CAD.

\section{INTRODUCTION}

In the recent years, demand for small antennas for wireless communication has increased tremendously hence, resulting extensive research on compact microstrip antenna design among microwave and RF engineers. A compact microstrip antenna such as VSAT systems is one of the most suitable applications to support high mobility satellite communication devices. Ku-band $(12-18 \mathrm{GHz})$ is one of the most preferred choices in VSAT systems. VSAT can be adopted for satellite television broadcast and satellite television [1]-[3]. Moreover, VSAT is a one of the best emergency communication backup system during disasters.

Microstrip patch antenna is a two dimensional planner antenna configuration having all the advantages of a printed circuit board which include but are not limited to easy to design, easy to manufacture and low cost. Though these antenna structures possess several advantages over other methods it also has some severe disadvantages which are low bandwidth, low gain, and low efficiency. There are many researches in progress in overcoming these disadvantages in order to make full use of advantages such as ease in design, ease in manufacturing and low cost in manufacturing these compact microstrip antennas.

The performances of these antennas are dependent upon their physical configuration. Various methods to improve the performance of antenna on their physical configuration are suggested by the researchers. Microstrip patch antennas are fed by methods that are categorized into contacting and non-contacting. In contacting methods, RF power is fed directly to the radiating patch using the connecting link which is the microstrip line [4]. While non-contacting, electromagnetic field coupling is conducted via transmission

Manuscript received March 5, 2014; revised July 15, 2014.

The authors are with National Broadcasting and Telecommunications Commission Bangkok, Thailand (e-mail: settapong.m@nbtc.go.th, jesada.s@nbtc.go.th,navneet.m@nbtc.go.th, nattakit.s.@nbtc.go.th). of power from microstrip line and radiating patch. "The four most popular feed techniques used are the microstrip line, coaxial probe (both contacting schemes), aperture coupling and proximity coupling (both non-contacting schemes)" [5].

In this paper, an E-shaped antenna structure is designed by cutting a notch in a rectangular microstrip patch antenna. Moreover, in this research, we consider the effect of very high operating frequency in $\mathrm{GHz}$ range which increases chances calculation error in the model. The proposed antenna in this paper can be used for broadcasting, remote sensing, aeronautical radio navigation and mobile satellite applications.

\section{ANTENNA DESIGN METHOdOLOGY}

To achieve the design objective in this research, first a rectangular microstrip patch antenna is constructed based on the standard designing procedure. For efficient radiation, a practical width of the rectangular patch element is [6]

$$
\mathrm{W}=\frac{1}{2 \mathrm{f}_{\mathrm{r}} \sqrt{\mu_{0} \varepsilon_{0}}} \sqrt{\frac{2}{\varepsilon_{\mathrm{r}}+1}}
$$

And the length of the antenna becomes [7], [8]

$$
L=\frac{1}{2 f_{r} \sqrt{\varepsilon_{e f f}} \sqrt{\varepsilon_{0} \mu_{0}}}-2 \Delta L
$$

where,

$$
\Delta L=0.41 h \frac{\varepsilon_{e f f}+0.3}{\varepsilon_{e f f}-0.258} \frac{\left(\frac{w}{h}+0.264\right)}{\left(\frac{w}{h}+0.8\right)}
$$

And

$$
\varepsilon_{e f f}=\frac{\varepsilon_{r}+1}{2}+\frac{\varepsilon_{r}-1}{2}\left(1+10 \frac{h}{w}\right)^{-B}
$$

where $B$ is given by:

$$
\begin{gathered}
B=0.564\left\{1+\frac{1}{49} \ln \left(\frac{(w / h)^{4}+(w / 52 h)^{2}}{(w / h)^{4}+.432}\right)+\frac{1}{18.7} \ln [1+\right. \\
\left.\left.\left(\frac{w}{18.1 h}\right)^{3}\right]\right\}\left(\frac{\varepsilon_{r}-0.9}{\varepsilon_{r}+3}\right)^{0.053}
\end{gathered}
$$

"where, $\lambda$ is the wave length, $f_{r}$ (in $\mathrm{Hz}$ ) is the resonant frequency, $L$ and $W$ are the length and width of the patch element, in cm, respectively and $\varepsilon_{r}$ is the relative dielectric constant." [6]

Prior to analyzing the frequency-dependent variables, the capacitance parameter in microstrip-line system should be analyzed. The capacitance per unit length of the classical 
parallel-plate capacitor is [7]:

$$
C=\varepsilon \frac{w}{h}
$$

A simple frequency-dependent capacitance of the parallel-plate capacitor can be expressed in any frequency-dependent attributes of $\varepsilon$ which is

$$
C(\omega)=\varepsilon_{0} \varepsilon^{*}(\omega) \frac{w}{h}
$$

where $\varepsilon^{*}(\omega)$ is a complex permittivity is expressed as $\varepsilon^{\prime}(\omega)-j \varepsilon "(\omega)$. Therefore,

$$
C(\omega)=\varepsilon_{0} \varepsilon^{\prime}(\omega) \frac{w}{h}-j \varepsilon_{0} \varepsilon^{\prime \prime}(\omega) \frac{w}{h}
$$

Referring to the equivalent Cole-Cole diagram deduced for a parallel-plate microstrip line in [8] is substitute into (8). Hence,

$$
C(\omega)=C\left(\frac{1}{1+Q(\omega)}\left[Q(\omega)+\frac{\varepsilon_{e f f}}{\varepsilon_{r}}\right]\right)-j \frac{C}{\varepsilon_{r}}\left[\varepsilon_{u}^{\prime \prime}(\omega)+\varepsilon_{c}^{\prime \prime}(\omega)+\varepsilon_{d}^{\prime \prime}(\omega)\right]
$$

where $C=\varepsilon_{0} \varepsilon_{r}(w / h)$.

For simplicity, the coefficients of (9) are defined as follows:

$$
\begin{gathered}
A(\omega)=\frac{1}{1+Q(\omega)}\left[Q(\omega)+\frac{\varepsilon_{e f f}}{\varepsilon_{r}}\right] \\
B(\omega)=\frac{1}{\varepsilon_{r}}\left[\varepsilon_{u}^{\prime \prime}(\omega)+\varepsilon_{c}^{\prime \prime}(\omega)+\varepsilon_{d}^{\prime \prime}(\omega)\right]
\end{gathered}
$$

In general, the characteristic impedance of a transmission line is given by

$$
Z_{0}=\sqrt{\frac{R+j \omega L}{G+j \omega C}}
$$

where $R, L, G, C$ are per unit length quantities defined as follows:

$R=$ resistance per unit length in $\Omega / \mathrm{m}$.

$L=$ inductance per unit length in $H / \mathrm{m}$.

$G=$ conductance per unit length in $S / \mathrm{m}$.

$C=$ capacitance per unit length in $F / \mathrm{m}$. [9]

If $G$ and $C$ are neglected, the characteristic impedance can be written as:

$$
Z_{0}=\sqrt{\frac{L}{C}}
$$

To achieve frequency-dependent characteristic impedance $\left(Z_{0}{ }^{\prime}(\omega)\right)$, the frequency-dependent capacitance $(C(\omega))$ of $(9)$ is replaced into the capacitance $(C)$ in (13). Therefore, frequency-dependent characteristic impedance is [9]

$$
Z_{0}^{\prime}(\omega)=\sqrt{\frac{L}{C[A(\omega)-j B(\omega)]}}=\frac{Z_{0}}{\sqrt{A(\omega)-j B(\omega)}}
$$

Now, the frequency-dependent (lossy) Smith-chart can be derived through input of $Z_{0}^{\prime}(\omega)$ in (14) into the normalized terminal impedance expression as done in traditional
Smith-chart model [9]. Therefore the normalized terminal impedance $Z_{L}^{\prime}$ is

$$
Z_{L}^{\prime}=\frac{Z_{L}}{Z_{0}^{\prime}(\omega)}=b r+j b x \quad(\text { Dimensionless })
$$

As $r$ and $x$ are the normalized resistance and normalized reactance, and $b=\sqrt{A(\omega)-j b(\omega)}$.

The voltage reflection coefficient of present Smith chart is

$$
\Gamma^{\prime}=\Gamma_{r}^{\prime}+j \Gamma_{i}^{\prime}=\frac{z_{L}^{\prime}-1}{z_{L}^{\prime}+1}
$$

or

$$
Z_{L}^{\prime}=\frac{Z_{L}}{Z_{0}^{\prime}(\omega)}=b r+j b x=\frac{\left(1+\Gamma_{r}^{\prime}\right)+j \Gamma_{i}^{\prime}}{\left(1-\Gamma_{r}^{\prime}\right)-j \Gamma_{i}^{\prime}}
$$

The procedure and formulas described above are used to construct an in-house MATLAB program. The calculated parameters are transferred to the software for simulation.

A rectangular microstrip patch antenna and ground plane dimensions of $W x L$ and $W_{g} x L_{g}$ respectively, as shown in Fig. 1. It is designed on a substrate with dielectric constant $\left(\varepsilon_{r}\right)$ and thickness $(h)$.

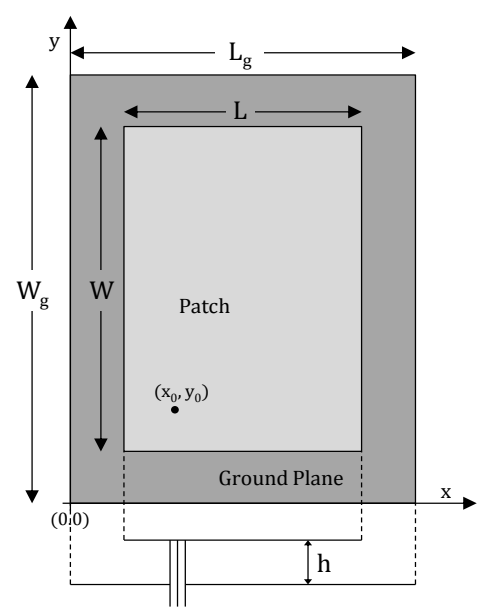

Fig. 1. Basic structure of a rectangular microstrip patch antenna.

Fig. 2 illustrates the E-shaped microstrip patch antenna by using cutting a notch technique to perturb the surface current patch and introducing local inductive effect [10]. By using this technique, it can create a multiband antenna [7], [11], [12].

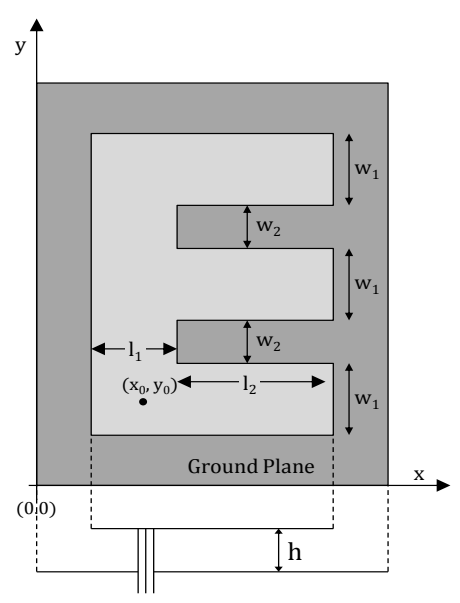

Fig. 2. Geometry of proposed antenna. 


\section{RESULTS AND DISCUSSIONS}

In this research, the design of simple rectangular microstrip antenna structure uses the cutting a notch to make it E-shapedas mentioned in Section II. This structure is further fed by using probe feed method. The simulation and analysis of the proposed antenna is done over in-house MATLAB program software.

The calculated parameters are transferred to the software for simulation. The proposed antenna is designed on FR4 substrate with dielectric constant of 4.2. According to the formulas, the antenna characteristics are shown in Table I.

\begin{tabular}{cc} 
TABLE I: E-SHAPED MiCROSTRIP PATCH ANTENNA CHARACTERISTICS \\
\hline \hline Parameters & Value $(\mathrm{mm})$ \\
\hline$\left(\mathrm{x}_{0}, \mathrm{y}_{0}\right)$ & $(15.35,18.95)$ \\
$\mathrm{h}$ & 1.5 \\
$\mathrm{l}_{1}$ & 6.5 \\
$\mathrm{l}_{2}$ & 9.45 \\
$\mathrm{w}_{1}$ & 5.75 \\
$\mathrm{w}_{2}$ & 2.95 \\
$\mathrm{~L}_{\mathrm{g}}$ & 26.5 \\
$\mathrm{~W}_{\mathrm{g}}$ & 32.85 \\
$\mathrm{~L}$ & 16.5 \\
$\mathrm{~W}$ & 22.75 \\
\hline \hline
\end{tabular}

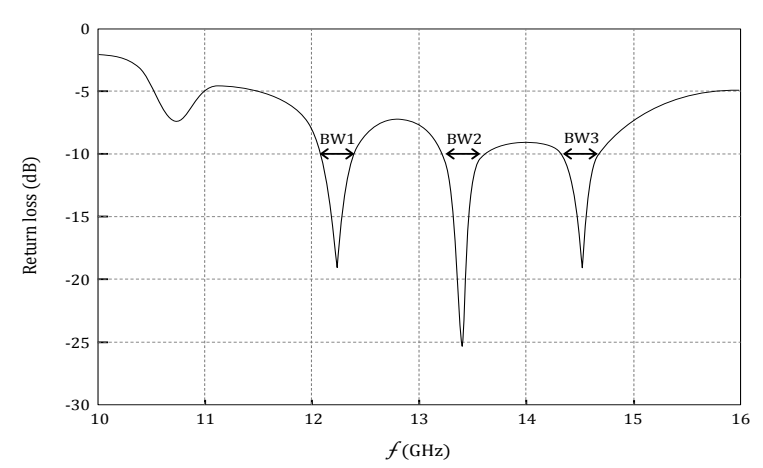

Fig. 3. Return loss of the proposed antenna.

From the Fig. 3, it is observed that the proposed antenna operates at the frequencies of $12.25 \mathrm{GHz}, 13.4 \mathrm{GHz}$ and $14.5 \mathrm{GHz}$ with return loss of $-17.5 \mathrm{~dB},-26 \mathrm{~dB}$ and $-15.5 \mathrm{~dB}$ respectively.

The bandwidth can be observed and calculated from the return loss at $-10 \mathrm{~dB}$. The results are shown in Table II.

TABLE II: BANDWIDTH (BW) OF THE PROPOSED ANTENNA

\begin{tabular}{cc}
\hline \hline Parameters & Value \\
\hline BW1 at $12.25 \mathrm{GHz}$ & $200 \mathrm{MHz}$ \\
BW2 at $13.4 \mathrm{GHz}$ & $250 \mathrm{MHz}$ \\
BW3 at $14.5 \mathrm{GHz}$ & $150 \mathrm{MHz}$ \\
\hline \hline
\end{tabular}

As indicated in the results, the operating frequencies of the proposed antenna comply with the $\mathrm{Ku}$-band. The $\mathrm{Ku}$-band is typically in the downlink frequencies of $10.7 \mathrm{GHz}$ to $12.75 \mathrm{GHz}$ and uplink frequencies of $13.75 \mathrm{GHz}$ to $14.5 \mathrm{GHz}$.

\section{CONCLUSIONS}

A compact E-shaped microstrip patch antenna is designed for Ku-band satellite communication applications. The operating frequencies of the proposed antenna are at $12.25 \mathrm{GHz}, 13.4 \mathrm{GHz}$ and $14.5 \mathrm{GHz}$ which cover the $\mathrm{Ku}$-band and provide good results in terms of bandwidth. The procedure proposed in this paper can be applied in CAD applications thus; practical implementation will be simple and effortless.

\section{ACKNOWLEDGMENT}

Financial support for this research paper is provided by National Broadcasting and Telecommunications Commission, Bangkok, Thailand.

\section{REFERENCES}

[1] S. Jana et al., "Single layer monopole hexagonal microstrip patch antenna for satellite television," International Journal of Soft Computing and Engineering, pp. 2231-2307, 2013.

[2] B. Sinhamahapatra, S. Jana, S. Dey, A. Das, B. Datta, M. Mukherjee et al., "Dual-band size deducted un-equal arm Y-shaped printed antenna for space communications," Int. Journal of Engineering, vol. 2, 2013.

[4] R. Saluja et al., "Analysis of bluetooth patch antenna with different feeding techniques using simulation and optimization," in Proc. International Conference on Recent Advances in Microwave Theory and Applications, 2008, pp. 742-744.

[5] V. V. Reddy and R. Rana, "Design of linearly polarized rectangular microstrip patch antenna using IE3D/PSO," bachelor theis, Department of Electronics and Communication Engineering, National Institute of Technology Rourkela, Rourkela, 2009.

[6] T. Huque, A. A. Chowdhury, K. Hosain, and S. Alam, "Performance Analysis of Corporate Feed Rectangular Patch Element and Circular Patch Element 4x2 Microstrip Array Antennas," International Journal of Advanced Computer Science \& Applications, vol. 2, 2011.

[7] R. Garg, Microstrip Antenna Design Handbook, Artech House, 2001

[8] C. A. Balanis, Antenna Theory: Analysis and Design, John Wiley \& Sons, 2012.

[9] S. Malisuwan, M. Charoenwattanaporn, U. Goenchanart, and V. Ungvichian, "Microstrip antenna for wireless LAN applications by applying modified smith-chart representation," Int. J. of The Computer, The Internet and Management, vol. 11, pp. 34-44, 2003

[10] M. Manohar, S. K. Behera, and P. K. Sahu, "Bandwidh enhancement with multi-band \&amp;multi-polarized rectangular microstrip patch antenna," in Proc. A Workshop on Advanced Antenna Technology, 2010 Indian Antenna Week, 2010, pp. 1-5.

[11] B.-K. Ang and B.-K. Chung, "A wideband E-shaped microstrip patch antenna for 5-6 GHz wireless communications," Progress In Electromagnetics Research, vol. 75, pp. 397-407, 2007.

[12] K. A. Hamad, "Design and enhancement bandwidth rectangular patch antenna using sinle trapezoidal slot technique," Journal of Engineering \& Applied Sciences, vol. 7, 2012.

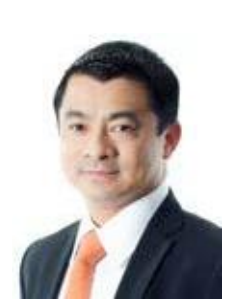

Settapong Malisuwan was born on March $24^{\text {th }}, 1966$, in Bangkok, Thailand. He received his $\mathrm{PhD}$ degree in electrical engineering (telecommunications), specializing in EMI/EMC from Florida Atlantic University (State University System of Florida), Boca Raton in 2000. He received an MSc degree in electrical engineering in mobile communications system, from George Washington University in 1996 an MSc degree in electrical engineering from Georgia Institute of Technology in 1992 and a BSc degree in electrical engineering from the Chulachomklao Royal Military Academy, Nakhon-Nayok, Thailand in 1990. He served in the Royal Thai Armed Forces for more than 25 years. His research interests are in efficient spectrum management and telecommunications policy and management. Col. Dr. Settapong Malisuwan is currently the elected vice chairman and a board member in the National Broadcasting and Telecommunications Commission, Thailand.

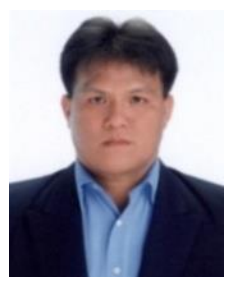

Jesada Sivaraks was born on May $12^{\text {th }}, 1970$ in Bangkok, Thailand. He received his MSEE degree from Oklahoma State University in 1996 and BEng degree from King Mongkut's Institute of Technology, Thailand. He completed his PhD degree in electrical engineering at Florida Atlantic University, Boca Raton, FL in 2001. Since 2011, he has been working in National Broadcasting and Telecommunications Commission as the secretary to the vice chairman. His 
$\mathrm{PhD}$ work is on the system aspects of Bluetooth, WLAN and mobile IP/CDPD. His current research interests are in telecommunication planning and related system analysis and efficient spectrum management. He is a member of Tau Beta Pi, Florida Epsilon and was an Honorary Advisory's Chairman of Science \& Technology committee of Parliament in 2009.

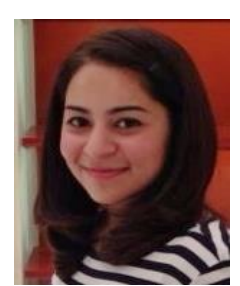

Navneet K. Madan was born in Bangkok, Thailand on April 22nd, 1987. She received her bachelor of business administration in international business management from Mahidol University in 2008, and received master of science degree in strategic management and marketing, Middlesex University, London, United Kingdom. She has been working as an assistant to vice chairman in National Broadcasting and Telecommunications, Bangkok, Thailand since January 2012. Her research interests are in spectrum management strategic flexibility, market orientation and environmental uncertainty in fast clock speed industries.

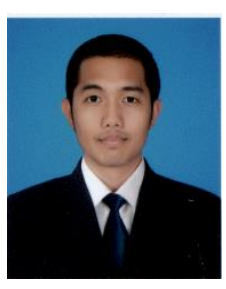

Nattakit Suriyakrai was born in Khonkhaen, Thailand on March $22^{\text {nd }}$, 1987. He received his bachelor of liberal arts in Japanese language from Thammasat University in 2010. He has been working as an assistant to vice chairman in National Broadcasting and Telecommunications, Bangkok, Thailand since November 2012. His research interests are in technology management and spectrum management. 